\title{
Imperforate hymen mimicking malignancy in adolescence
}

\author{
Pinar Solmaz Hasdemir ${ }^{1}$, Mustafa Farasat ${ }^{2}$, Halil Ibrahim Tanriverdi ${ }^{3}$ \\ ${ }^{1}$ CELAL BAYAR UNIVERSITY SCHOOL OF MEDICINE, DEPARTMENT OF OBSTETRICS \& GYNECOLOGY, MANISA, TURKEY \\ ${ }^{2}$ CELAL BAYAR UNIVERSITY SCHOOL OF MEDICINE, DEPARTMENT OF RADIOLOGY, MANISA, TURKEY \\ ${ }^{3}$ CELAL BAYAR UNIVERSITY SCHOOL OF MEDICINE, DEPARTMENT OF PEDIATRIC SURGERY, MANISA, TURKEY
}

\begin{abstract}
Imperforate hymen is a rare congenital abnormality. It often presents with abdominal mass associated with pain. Differential diagnosis includes abdominal malignancies.

A thirteen years-old female was referred to our center with abdominal distention and pain with the presumptive diagnosis of abdominal malignancy. Serum levels of tumor markers were extremely high. Abdominal CT scan without contrast revealed an extremely large, cystic mass (hematocolpos) with thickened walls. Gynecologic examination revealed imperforated hymen. A midline vertical hymenal incision was performed.

This case is unique in terms of high suspicion of malignancy in light of physical examination, CT scan characteristics and high levels of tumor markers. It emphasizes that gynecologic examination should be a part of routine physical examination in adolescent females presenting with abdominal mass.
\end{abstract}

Category: Case Presentation

Received: June 15, 2020

Accepted: August 10, 2020

Keywords:

adolescence, imperforated hymen, malignancy, tumor markers

*Corresponding author:

Pinar Solmaz Hasdemir,

Celal Bayar University School of Medicine, Department of Obstetrics \& Gynecology, Manisa, 45000 Turkey

E-mail: solmazyildiz@yahoo.com

\section{Introduction}

Imperforate hymen is a rare congenital abnormality with an incidence of $0.05-0.1 \%$ [1]. It occurs when the hymen, an embryological remnant of mesodermal tissue, fails to perforate during the later stages of embryo development [2]. Clinical presentations include abdominal pain that usually accompanies an abdominal mass and primary amenorrhea.

\section{Case Presentation}

A thirteen years-old female presented with abdominal distention associated with pain. Her symptoms started three months ago and got worse for the last 10 days. She was referred to our medical center with the presumptive diagnosis of abdominal malignancy. She was initially evaluated by the surgical team. In physical examination, an extremely tender to touch abdominal mass was noted.

Laboratory analysis revealed elevated white blood cell count of $10.93 \times 10^{3} / \mu \mathrm{L}$ (normal range $4-10.5 \times 10^{3} / \mu \mathrm{L}$ ), mild anemia with hemoglobin of $11.1 \mathrm{~g} / \mathrm{dL}$ (normal range 12.5-15 g/dL), mildly elevated serum LDH level of 333
U/L (normal range 0-247 U/L), elevated serum CA-125 level of $130.5 \mathrm{U} / \mathrm{mL}$ (normal range $0-35 \mathrm{U} / \mathrm{mL}$ ), remarkably elevated serum CA $19-9$ level of $1860.7 \mathrm{U} / \mathrm{mL}$ (normal range 0-35 U/mL) and elevated serum CRP level of $1.7 \mathrm{mg} / \mathrm{dL}$ (normal range $0-0.5 \mathrm{mg} / \mathrm{dL}$ ).

Abdominal CT scan without contrast revealed an extremely large (147x125x304 mm in diameter), cystic mass with thickened walls. The cyst density was measured 30-40 HU in the posterior and 15-20 HU in the anterior, suggesting new and old bleeding. The mass was extending from the pelvic floor to renal level. Bilateral ureters were dilated due to compression of the mass. The omental tissue was thickened indicating potential inflammation or malignancy. There was no lateralization. The ovaries were not visualized separately. Based on the appearance, midline location and extension of the mass, the possibility of hematocolpos was considered (Figure 1).

On additional questions, it was noted that she has not experienced menstruation despite her breast development and pubic hairiness starting two years ago. Gynecological examination in the light of the anamnesis and CT scan report revealed bulging imperforated hymen (Figure 2). A 
midline vertical hymenal incision 1 to $2 \mathrm{~cm}$ was made under general anesthesia and $4000 \mathrm{cc}$ dark, non-coagulated blood evacuated after getting the informed consent of the patient and her parents. A 22-inch urinary Foley catheter was placed to vagina for drainage (Figure 2). Foley catheter was removed 24 hours later. Her symptoms resolved completely and discharged on the second day of the operation. Prophylactic antibiotherapy was prescribed on discharge. The patient had no complaints at 6 months follow up.

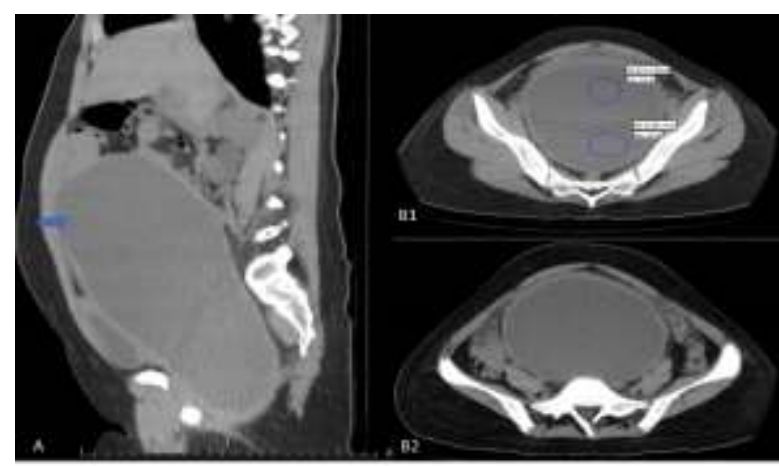

Figure 1. (A) The axial section imaging of the giant hematocolpos (the thick arrow). The thin arrow shows the uterus. (B1) The sagittal section of the mass showing density gradient (circles). (B2) The omental thickness (arrows) mimicking malignancy.

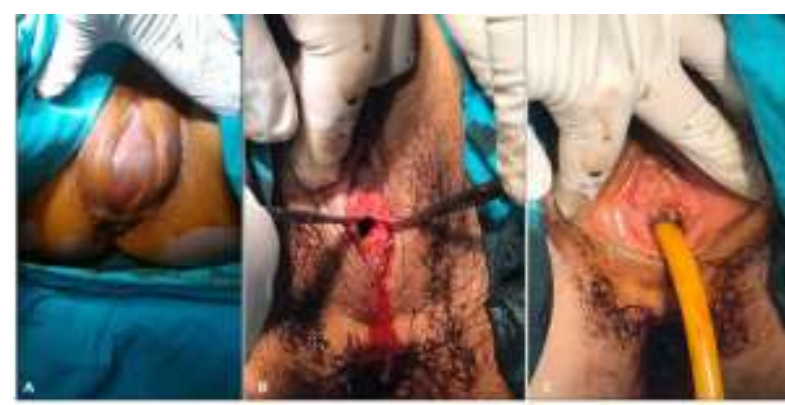

Figure 2. (A) Image of the bulging hymenal tissue during gynecologic examination. (B) Appearance of the incision. (C) Image of the inserted Foley catheter at the end of the operation.

\section{Discussions}

Imperforated hymen is classified as V3 in ESHRE/ESGE Classification System [3]. Age of presentation can vary from newborn to adolescence. Clinical presentation can mimic many pathologies from appendicitis to malignancies [4,5]. The most dramatic presentation in those cases is to have a giant abdominal mass showing malignant characteristics accompanying highly elevated tumor markers. First imperforated hymen mimicking malignancy case was reported in 1958 by Rosenthal $\mathrm{AH}$. et al [5]. There are 3 additional cases in literature reported imperforated hymen with mild to moderate elevation of CA-125 and CA 19-9 levels [6-8].
None of these case reports gave a detailed description of hematocolpos related abdominal pathologies in imaging modalities.

\section{Conclusions}

Our case is unique in terms of high suspicion of malignancy in light of physical examination, CT scan characteristics (thickened wall abdominal mass with hemorrhagic content, thickening of adjacent omental tissue) and extremely elevated levels of tumor markers. This case emphasizes that gynecologic examination should be a part of routine physical examination in adolescents presenting with abdominal mass in order to prevent unnecessary surgical procedures.

\section{Conflict of interest disclosure}

There are no known conflicts of interest in the publication of this article. The manuscript was read and approved by all authors.

\section{Compliance with ethical standards}

Any aspect of the work covered in this manuscript has been conducted with the ethical approval of all relevant bodies and that such approvals are acknowledged within the manuscript.

\section{References}

1. Basaran M, Usal D, Aydemir C. Hymen sparing surgery for imperforate hymen: case reports and review of literature. J Pediatr Adolesc Gynecol. 2009;22(4): e61-e64. doi:10.1016/j.jpag.2008.03.009

2. Lazanyi M, Grover SR. Imperforate hymen: Retrospective review from a single tertiary centre of presenting symptoms and diagnostic process. J Paediatr Child Health. 2020; 56(1): 90-93. doi: 10.1111/jpc. 14501

3. Grimbizis GF, Gordts S, Di Spiezio Sardo A, et al. The ESHRE/ESGE consensus on the classification of female genital tract congenital anomalies. Hum Reprod. 2013; 28(8): 2032-2044. doi: 10.1093/humrep/det098

4. Amponsah-Manu F, Ssentongo P, Arkorful T, et al. Imperforate hymen and leaking hematosalpinx mimicking acute appendicitis: A report of a rare case and a review of literature. Int J Surg Case Rep. 2019;63:69-74. doi:10.1016/j.ijscr.2019.09.003

5. ROSENTHAL AH, BLOCK RE, LAPIN A. The imperforate hymen as a cause of abdominal tumor. Am J Surg. 1958;95(3):487-488. doi:10.1016/00029610(58)90558-0 
6. Partsinevelos GA, Rodolakis A, Loutradis D, Antsaklis A. Imperforate hymen is associated with elevated serum CA125 and CA19-9 levels: a reappraisal. $J$ Obstet Gynaecol. 2009; 29(6): 560-561. doi: 10.1080/01443610902984979

7. Buyukbayrak EE, Ozyapi AG, Karsidag YK, Pirimoglu $\mathrm{ZM}$, Unal O, Turan C. Imperforate hymen: a new benign reason for highly elevated serum CA 19.9 and CA 125 levels. Arch Gynecol Obstet. 2008;277(5):475477. doi:10.1007/s00404-007-0493-3

8. Sak ME, Evsen MS, Soydinc HE, Sak S, Yalinkaya A. Imperforate hymen with elevated serum CA 125 and CA 19-9 levels. J Reprod Med. 2013;58(1-2):47-50. 